\title{
MELHORIA DE PROCESSO EM UMA UNIDADE DO DETRAN-SP: UMA ANÁLISE SEGUNDO OS PRINCÍPIOS DO LEAN OFFICE
}

\section{PROCESS IMPROVEMENT IN A DETRAN-SP UNIT: AN ANALYSIS ACCORDING TO THE PRINCIPLES OF LEAN OFFICE}

\author{
Ricardo Milanez de Siqueira* E-mail: ricardosiqueira2007@hotmail.com \\ Ethel Cristina Chiari da Silva* E-mail: e-chiari@uol.com.br \\ Universidade de Araraquara (UNIARA), Araraquara, SP
}

Resumo: A preocupação com a qualidade e eficiência dos serviços atingiu também o ambiente público. O objetivo dessa pesquisa é apresentar o processo de melhoria implantado em uma unidade de trânsito do Departamento Estadual de Trânsito do Estado de São Paulo sob à luz da teoria do lean office. Esse estudo apresenta uma pesquisa exploratória que traz a contextualização do setor público e do lean office, apresentando algumas aplicações de sucesso no ambiente público. A pesquisa caracteriza-se como um estudo de caso de natureza qualitativa, em que os dados foram coletados por meio da análise documental e do sistema de gestão do órgão e da observação direta. Após o levantamento desses dados, foi mapeado o fluxo de valor do processo de emissão do CRLV (Certificado de Registro e Licenciamento de Veículo), pois tal processo é importante nas rotinas de funcionamento desse órgão. Em seguida, detalharam-se as alterações desse procedimento administrativo, além disso, relatou-se a inclusão de tecnologias de suporte. Ao final observou-se como resultados a redução do lead time de 2 dias úteis para no máximo 1 hora. Além disso, essa mudança resultou em uma redução no consumo de aproximadamente 9300 folhas de papel em um ano só nessa unidade em estudo, desse modo colaborando para a questão ambiental. Assim, os conceitos do lean office aplicados nesse ambiente público foram bem sucedidos, podendo servir de modelo para outros órgãos de trânsito do país.

Palavras-chave: Lean office. Mapeamento de fluxo de valor. Administração pública. Detran.

\begin{abstract}
The concern with the quality and efficiency of services has also affected the public environment. The objective of this research is to present the improvement process implemented in a transit unit of the State Department of transit of the state São Paulo under the light of the lean office theory. This study presents an exploratory research that brings the contextualization of the public sector and lean office, presenting some successful applications in the public environment. The research is characterized as a case study of a qualitative nature, in which the data were collected through documentary analysis and the organ management system and direct observation. After this data was collected, the value flow of the CRLV (Vehicle Registration and Licensing Certificate) process was mapped, as this process is important in the routines of this body. Next, the changes of this administrative procedure were detailed, in addition, the inclusion of support technologies was reported. At the end it was observed as results the lead time reduction from 2 working days to a maximum of 1 hour. In addition, this change helped to reduce the consumption of approximately 9300 sheets of paper in a single year in this unit under study, thus contributing to the environmental issue. Thus, the concepts of lean office applied in this public environment were successful, being able to serve as a model for other transit agencies of the country.
\end{abstract}

Keywords: Lean Office. Value Stream Mapping. Public Management. Detran. 


\section{INTRODUÇÃO}

O setor público brasileiro está buscando aumentar a qualidade nos serviços prestados pelo Estado. Esse avanço está ocorrendo nos modelos de gestão com o objetivo de aumentar a eficiência na execução, no controle e nos resultados previstos nos planos governamentais (PISA; OLIVEIRA, 2013). Além disso, o poder público está focado para que os recursos financeiros oriundos dos impostos sejam utilizados de forma eficiente, eficaz e efetiva (OLIVEIRA et al., 2017).

Segundo Gomes e Martins (2013) essa nova forma de gerir o sistema público está focada em resultados mais eficientes, no cidadão e no aumento da transparência, investindo, para isso, em tecnologia da informação.

Após os anos 90, segundo Fadul e Souza (2006) o Brasil inicia um processo de mudança no pensamento, passando do burocrático para o gerencialista, que objetiva combater a ineficiência, a baixa qualidade oferecida pelo serviço público e para Sartor (1998) a gestão gerencialista prioriza também a redução dos custos.

Segundo Turati (2007) as práticas utilizadas no setor privado principalmente no setor manufatureiro, desde que, adaptadas para os setores administrativos públicos, podem apresentar resultados positivos no que tange à eficiência e à economia. Para Gissoni (2016) a conquista da eficiência na prestação do serviço público exigida pelos usuários pode ser alcançada com a melhoria dos processos administrativos, tornando-os mais ágeis e menos burocráticos.

$\mathrm{Na}$ presente pesquisa, foram analisados os procedimentos realizados pela unidade de trânsito do Departamento Estadual de Trânsito do Estado de São Paulo (DETRAN-SP) localizada em Cedral. Tal órgão público possui uma estrutura em que as solicitações realizadas pelo cidadão passam por diversos setores, tornando o serviço burocrático e moroso.

Diante disso, esse setor público necessita de inovações técnicas e processuais para aperfeiçoar o serviço prestado ao cidadão, buscando atendê-lo com presteza, qualidade e agilidade. Para isso, foi realizado o Mapeamento de Fluxo de Valor (MFV) dos procedimentos realizados por essa unidade de trânsito para a emissão do Certificado de Registro e Licenciamento de Veículo (CRLV), com a finalidade de melhorar a eficiência e os resultados desse departamento. Gronovicz 
et al. (2013) mencionam que esse mapeamento para o setor de serviços é mais complexo quando comparado ao da manufatura.

Assim, a problemática desse estudo está justamente em estudar a aplicação dos conceitos do lean office em um ambiente administrativo público de uma unidade de trânsito do DETRAN-SP.

Portanto, o objetivo dessa pesquisa é investigar os processos de melhoria implantados em uma unidade de trânsito do DETRAN-SP sob a luz da teoria do lean office, mais especificamente, o processo de emissão do certificado de registro e licenciamento de veículo (CRLV).

Para atingir o objetivo proposto, o trabalho partiu de uma revisão bibliográfica como suporte para o desenvolvimento de um estudo de caso. O texto está organizado em 6 seções, sendo a primeira essa introdução que contextualizou o trabalho, apresentou o objetivo e a justificativa; a segunda seção trata-se do referencial teórico de suporte ao trabalho, nessa seção aborda-se a administração pública, a origem e aspectos da manufatura enxuta e, na sequencia, o lean office e o mapeamento do fluxo de valor; a seção 3 detalha o método de desenvolvimento da pesquisa, após apresenta-se a seção 4 com o estudo de caso; a seção 5 apresenta os resultados e discussões; a seção 6 traz as principais conclusões e considerações sobre o trabalho e, por fim, as referências desse texto.

\section{REFERENCIAL TEÓRICO}

\subsection{Administração Pública}

A administração pública brasileira está dividida em duas formas de atuação: direta e indireta. A administração direta apresenta órgãos e entidades que estão vinculados diretamente ao chefe do Poder Executivo, mas nenhum desses órgãos vinculados tem personalidade jurídica própria. Além disso, não apresenta patrimônio próprio (FONSECA, 2014). Por outro lado, a administração pública indireta, apresenta personalidade jurídica e patrimônio próprios e suas despesas são custeadas por um orçamento próprio, como as autarquias que é o caso do DETRANSP (PEREIRA, 2012). No caso do DETRAN-SP, foi a partir Lei Complementar 1195/2013 do Estado de São Paulo que esse departamento migrou da administração direta para a indireta. 
Para Guerreiro (2013), toda administração pública obedecerá a celebração de contratos, a condução de processos e aos princípios básicos que norteiam os atos administrativos e normativos, a saber: legalidade, impessoalidade, moralidade, publicidade e também a eficiência (PLANALTO, 2018).

\subsection{Características básicas do órgão público}

Essa seção traz algumas características exclusivas que dificultam a gestão do serviço público quando comparado à iniciativa privada.

As contratações realizadas pelo setor público, não possuem a mesma autonomia das empresas privadas, pois a área pública é obrigada a seguir às regras estabelecidas pela lei das licitações de no 8666/93 (ALTOUNIAN, 2009). Portanto, segundo Kuhn (2002) essa legislação limita a liberdade da administração pública e consequentemente de seus administradores e servidores.

Outro fator que segundo Turati (2007) é exclusivo do setor público é a constante mudança do chefe do Poder Executivo, já que a cada quatro anos ele é substituído por outro, a menos que ele seja reeleito. A estabilidade funcional da maioria dos servidores públicos, faz com que, infelizmente, muitos não desempenham devidamente suas funções, afetando os serviços prestados a população.

Então, é possível observar que a realização de alterações no ambiente público como compra de equipamentos, construção e reforma de prédios públicos ou até mesmo mudança nos procedimentos exigem muito trabalho e empenho. Todos esses empecilhos são notados nesse departamento estadual de trânsito já que seu diretor geral é nomeado ou exonerado conforme a vontade do governador. Além disso, as compras de material para uso diário ou equipamentos de informática necessitam de processo licitatório, e até mesmo uma alteração de procedimento administrativo necessita de legislação.

\subsection{Modelos básicos de gestão pública}

Essa seção traz os três principais modelos de gestão pública praticados pelos governos ao longo dos tempos: patrimonialista, burocrático e gerencialista. 
O modelo de gestão patrimonialista deixa o Estado bastante suscetível à corrupção, gerontocracia, nepotismo, pois a nomeação dos cargos públicos em confiança como ministros, secretários são baseados na lealdade política (LIMA, 2008; SECCHI, 2009).

O modelo de gestão burocrático para Lima (2008) está focado no controle rígido das ações do ente público, deixando de lado a missão que é servir o cidadão com qualidade e eficiência. Além da presença excessiva de papel e do rigor da hierarquia, tornando o serviço oneroso e ineficaz, afetando diretamente os serviços ofertados para os cidadãos (SILVA, 2011).

O modelo de gestão gerencialista para Secchi (2009) prioriza a eficiência, a eficácia e a competividade, já para Mazza (2011) esse modelo está centrado no controle dos resultados. Embora esse modelo seja inspirado no setor privado, segundo Turati (2007) esse setor adquiri suas receitas a partir da venda de produtos e serviços para seus clientes, porém a receita do Estado é proveniente de impostos e taxas recolhidas pelo cidadão.

\subsection{Lean manufacturing (manufatura enxuta)}

Segundo Dennis (2008) o STP (Sistema Toyota de Produção) surgiu no contexto do pós-guerra. Nesse período o Japão enfrentava dificuldades inclusive na área econômica, necessitando de melhorias em seu sistema de produção. Em tese, segundo Ohno (1997) a ideia principal da produção enxuta é a redução dos setes desperdícios identificados.

Slack et al. (1999) citam e descrevem os sete desperdícios que ocorrem na produção:

- Superprodução: produção prematura ou em excesso, produzindo estoque;

- Espera: lead time elevado, ocasionado pelo vasto tempo ocioso de processo produtivo devido à espera de pessoas ou de peças.

- Transporte: compreende a movimentação excessiva de peças e pessoas, ocasionando gastos desnecessários. Processos: a utilização de sistemas e procedimentos de forma desnecessários ou excessivas revisões, contribuirá para desperdícios. 
- Estoque: de matéria prima, de produto em processo ou ainda de produto acabado; qualquer tipo de estoque desnecessário colabora para o aumento de custos.

- Movimentação: ambiente desorganizado e a circulação excessiva de pessoas, ocasionam o extravio de itens, prejudicando também o desempenho no que se refere à ergonomia.

- Defeito: produto com a qualidade prejudicada, se torna bem preocupante, haja vista que necessitam de retrabalho, aumento custos e também colabora para a insatisfação no cliente.

Para a eliminação desses sete desperdícios, os cinco princípios mencionados a seguir, são peças importantes. Embora esses princípios não sejam facilmente alcançados, direcionam a empresa que deseja uma transformação para a filosofia lean (HINES; TAYLOR, 2000). Além disso, por serem princípios bem gerais, tal fato contribui para que a filosofia enxuta seja disseminada para vários seguimentos (COSTA; JARDIM, 2010; CABETE, 2016).

Segundo Womack e Jones (2004), os princípios são:

$1^{\circ}$ Especifique o que é valor para cada tipo de produto, focando sempre no cliente;

$2^{\circ}$ Identifique o fluxo de valor para cada produto, com o objetivo de não gerar desperdícios;

3 ํ Elabore um fluxo de valor contínuo, evitando esperas;

$4^{\circ}$ Elabore um fluxo de valor puxado pelo cliente;

5 Busque a perfeição por meio da melhoria continua.

Esses cinco princípios foram adaptados para as atividades de serviços com o objetivo de aplicá-los em ambiente administrativo, surgindo o conceito do lean office (LAGO; CARVALHO; RIBEIRO, 2008).

\subsection{Lean office}

A origem do lean está direcionada para o setor manufatureiro, todavia há relatos de estudos e aplicação em outras áreas entre elas: áreas administrativas e no serviço público (TEGNER.et al, 2016). Além disso, segundo Welo e Ringer (2015) 
o conceito do lean, embora tenha sido criado para as fábricas, também é utilizado em escritórios e nas instituições públicas.

Para Tapping e Shuker (2010), a utilização e a aplicação dos conceitos provenientes do STP no setor administrativo é definido como lean office. Complementam Pagnossin e Ross (2016) que esse novo conceito nada mais é que uma adaptação e uma evolução do lean manufacturing. De acordo com Turati (2007) - lean manufacturing e o lean office apresentam a mesma finalidade, pois estão focados na redução ou na eliminação das perdas existentes nos processos tanto no ambiente da fábrica quanto no ambiente administrativo. Porém, os processos do chão de fábrica são mais visíveis, pois os desperdícios como sucatas e retrabalhos são mais evidentes e percebidos facilmente (ZAKI, 2009). Diante disso, para Campos et al (2016) essa aplicação nos ambientes administrativos é um desafio já que os processos são abstratos.

Outra característica do ambiente administrativo segundo Lago, Carvalho e Ribeiro (2008) é a utilização de documentos e assinaturas desnecessários, além de processos extremamente burocráticos.

Diante do exposto, a minimização ou a eliminação dos trâmites, das impressões, dos relatórios e de cópias desnecessárias, ocasionam um impacto nos serviços desse órgão público. Segundo Turati (2007) a utilização do lean office no ambiente público administrativo colabora para a melhoria no atendimento, aumentando o nível de satisfação do cidadão, devido a redução no tempo de espera dos pedidos.

Além disso, essa redução de processos está diretamente relacionada com gastos e com a área ambiental, já que haverá redução no consumo de papel. Então, aplicar tal conceito nessa unidade do DETRAN provocará impactos positivos. Todavia, antes será necessário identificar os desperdícios dessa unidade, e de acordo com Tapping e Shuker (2010), os sete desperdícios do ambiente administrativo que precisam ser identificados para posteriormente serem eliminados são:

1) Superprodução: produção excessiva seja informações ou de papéis. Esses excessos segundo Lareau (2002) deixa o processo ainda mais burocrático; 
2) Espera: tempo utilizado aguardando assinaturas do superior (LAREAU, 2002);

3) Processamento: geralmente, está vinculada a atividades como verificação de um trabalho já realizado por outra pessoa, ou seja, são basicamente revisões em excesso;

4) Estoque: está relacionado a todo e qualquer produto, todavia o mais comum, nesse ambiente são cópias e arquivos desnecessários;

5) Movimentação: que não agregam valor na perspectiva do cliente, por exemplo, o layout da empresa;

6) Defeitos: originados a partir de itens que precisam de uma correção, pois estão defeituosos, exemplo comum nesse setor: informações incorretas ou errôneas;

7) Transporte: movimentação exagerada de informações, de pessoas, papéis e arquivos.

Após a descrição, verificação e a constatação dos sete desperdícios de um ambiente administrativo, Tapping e Shuker (2010) propõem oito passos para a implantação e manutenção do lean office, entre eles: comprometer-se com o lean, escolher o fluxo de valor, aprender sobre o lean, mapear o estado atual, identificar as métricas do lean, mapear o estado futuro, criar planos kaizen e implementar os planos kaizen.

Além desses oito passos, esses mesmos autores mencionam que para a implantação seja bem sucedida é importante que:

1) Exista um comprometimento verdadeiro com a melhoria do fluxo de valor;

2) Demanda do cliente seja compreendida;

3) O fluxo de valor seja demostrado com exatidão por meio da utilização do mapa de estado atual;

4) Exista uma comunicação intensa com todos os envolvidos no fluxo de valor.

\subsection{Mapeamento de fluxo de valor}

O Mapeamento do Fluxo de Valor (MFV), é uma ferramenta simples, pois utiliza papel e lápis com o objetivo de facilitar o entendimento do fluxo de material Revista Produção Online. Florianópolis, SC, v. 20, n. 2, p. 368-397, 2020 
(tangível) e de informação (intangível). O MFV também é considerado uma ferramenta da Engenharia de Produção com a finalidade de organizar o ambiente de trabalho, tal ferramenta também está inserida na filosofia lean office que está sendo utilizada pelo setor público (CORREA; CORREA, 2006). Complementa Emiliani e Stec (2005) que o MFV também poderá ser utilizado para mapear qualquer atividade do setor de serviços inclusive na área pública. Para Tapping e Shucker (2010) o pensamento lean e o MFV estão em expansão para os mais diversos setores, pois essa ferramenta de mapeamento está presente nas atividades de escritório.

Além dessas aplicações, Pinto (2009) menciona que esse mapeamento é uma excelente ferramenta para iniciar um projeto lean na organização pois:

1. Permite uma visão de toda a cadeia de valor, e não somente de partes isoladas do processo;

2. Colabora na identificação e origem dos desperdícios considerados pelo lean.

3. Oferece uma linguagem simples, comum e intuitiva;

4. Fornece uma base para o desenvolvimento de um plano de ação em implantação;

5. Exibe a conexão entre o fluxo de materiais de informações e o de capital.

Para a construção e elaboração do MFV segundo Rother e Shook (1999) é necessária uma divisão em cinco etapas básicas:

1) Identificar o produto;

2) Criar um MFV do estado atual;

3) Avaliar o MFV do estado atual e identificar os problemas;

4) Criar um MFV do estado futuro;

5) Implementar o plano final.

Além dessas etapas, segundo Benetti (2010), o mapeamento exige alguns procedimentos como: selecionar uma família de produtos; desenhar ou mapear o estado atual e o estado futuro, o plano de trabalho e a implementação, conforme proposto também por Rother e Shook (2009) na figura 1. 


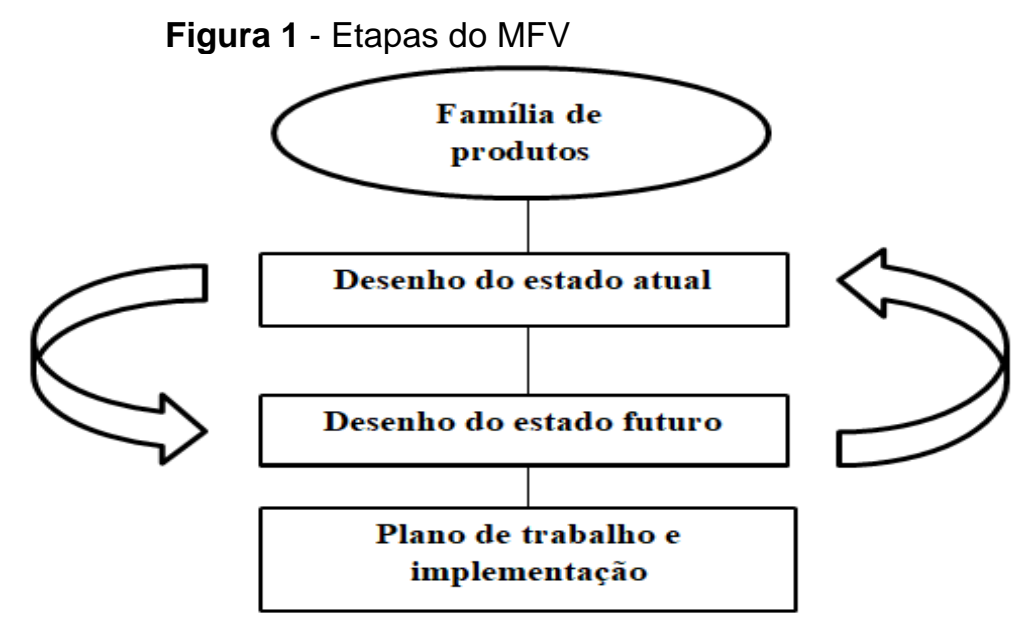

Fonte: Adapetado de Rother e Shook (2009, p.9).

A base do MFV assim como suas técnicas não são recentes, pois já era utilizada no setor de manufatura na linha de produção do Japão desde o final de 1980 (SHOOK, 2008). Todavia, segundo Fontanini e Picchi (2005) as ferramentas lean, utilizadas inicialmente no ambiente fabril, necessitam de adaptações e ajustes para que sejam aplicadas nos ambientes administrativos. Segundo Krings et al. (2006) a adoção dos princípios lean nos ambientes administrativos conquistaram uma diminuição dos desperdícios oriundos do processamento de informações, do manuseio de papéis, na presteza dos prazos e principalmente um avanço no atendimento dos clientes.

De acordo com Rother e Shook (2012), é vantajoso aplicar o MFV, pois:

1) Colabora para a visualização do fluxo como um todo e não mais processos individuais;

2) Reconhece as perdas e ajuda na identificação dos locais de desperdícios;

3) Utiliza uma linguagem simples para representar os processos;

4) Deixa o fluxo mais visível, facilitando o seu entendimento e discussões;

5) Une conceitos e técnicas lean;

6) Ajuda na elaboração dos planos de implementação de melhorias;

7) Deixa explícita a relação do fluxo de informação e o do fluxo de material;

8) O MFV é uma ferramenta mais útil quando comparada com outras ferramentas quantitativas como quantidade de estoques, lead time, distância percorrida e diagramas de layout já que essas trazem um passo a passo que não agregam valor. 
Embora o MFV apresente essas vantagens, segundo Solding e Gullander (2009) essa ferramenta, possui limitações, já que se trata de uma representação estática do fluxo de valor. Então, esse mapeamento não é uma técnica que solucionará todos os problemas de uma empresa ou departamento. Apesar disso, ainda assim segundo Manos (2006), o mapeamento representa uma das mais poderosas ferramentas que compactuam o processamento de materiais e também o fluxo de informações.

\subsection{Mapeamento de fluxo de valor em ambiente administrativo}

O MFV proposto por Tapping e Shuker (2010) é utilizado na identificação do fluxo de materiais e informações. Porém, no ambiente administrativo, o fluxo de valor está mais concentrado e relacionado com o fluxo de informações (LIMA et al., 2010).

Segundo Rother e Shook (2012), devido a isso, o mapeamento em setores administrativos pode apresentar padrões diferentes dos observados para o fluxo de materiais, pois para Lopez, Requena e Lobera (2015) o mapeamento no setor administrativo colabora para localizar os problemas de um serviço, permitindo aumentar seu desempenho.

Então, Tapping e Shuker (2010) recomendam adaptações para a aplicação do MFV no setor administrativo para mapear o fluxo de informações. Segundo esses autores as alterações são necessárias, pois as características do serviço oferecido são: processamento de informações, processos administrativos são dependentes das pessoas, o tempo de cada processo sofre grande variação, os estoques existentes são intangíveis, os retrabalhos e erros praticamente não são relatados e pequena padronização dos processos.

E para representar o MFV sugere-se a utilização de desenhos, conforme a figura 2. Os fluxos são representados por meio da utilização de desenhos simples, sendo assim, sem a necessidade de softwares especializados ou de computadores. (LOPEZ; REQUENA; LOBERA, 2015). 
Figura 2 - Simbologia utilizada em MFV para escritórios

Ícones do Mapeamento do Fluxo de Valor

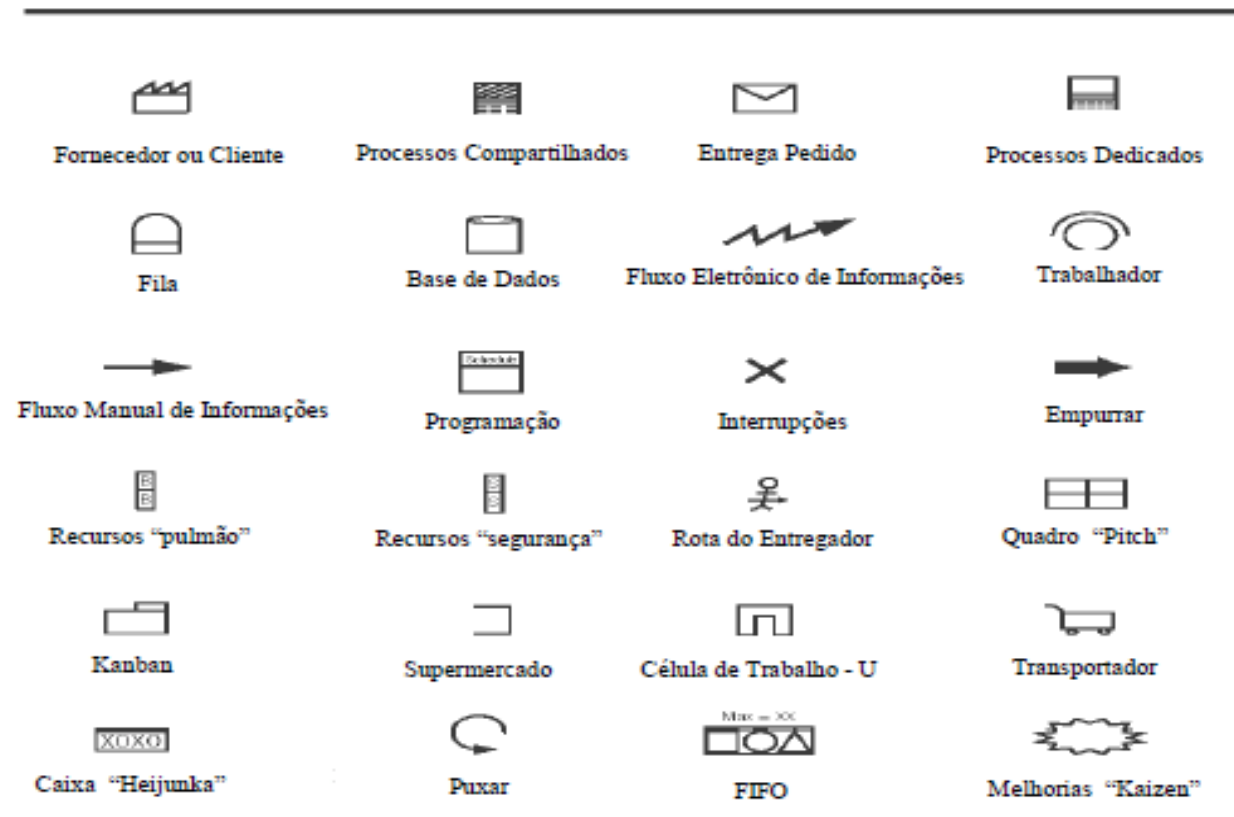

Fonte: Tapping e Shuker (2010, p.66).

Esse mapeamento é importante, pois para Carter (2010) antes de aplicar ferramentas lean em ambientes administrativos, é necessária a compreensão do fluxo de trabalho e das informações, pois o foco do mapeamento é reduzir o lead time dos processos, eliminando desperdícios. Para Rother e Shook (2003) o MFV possui o objetivo de demonstrar de forma clara a visualização dos processos, procurando otimizar o fluxo e eliminar de perdas e a diminuição do lead time. Segundo Prates e Bandeira (2012), esses desperdícios são tratados pela filosofia lean como procedimentos (atividades) que exigem recursos, todavia, não agregam valor.

\subsection{Aplicações do MFV em ambiente administrativo público brasileiro}

Costa e Moreira (2018) avaliaram trâmites internos da Universidade Federal do Rio Grande do Norte, utilizando o mapeamento de processos com a finalidade de melhorar os serviços oferecidos aos usuários/cidadãos. O resultado alcançado foi um aumento na agilidade dos trâmites, redução de tempo e melhoria na comunicação interpessoal dos setores estudados. 
Boriolo (2018) estudou a utilização de ferramentas do lean office na Universidade Federal de São Carlos com o intuito de otimizar o processo e adequálo às regras da gestão documental do Arquivo Nacional. Uma das ferramentas foi o MFV a qual permitiu a identificação de atividades que não agregavam valor como a falta de padronização entre as equipes do arquivamento, setores com procedimentos não especificados e também inadequações no fluxo. O resultado conquistado por esse estudo foi uma melhoria no fluxo dos documentos públicos dessa instituição e a adequação às normas impostas pelo Arquivo Nacional.

Romualdo (2018) analisa o processo de vistoria veicular para renovação do licenciamento anual no Detran do Rio de Janeiro. Após a aplicação de ferramentas do lean e com auxílio do MFV, constatou-se que o processo para realização dessa vistoria apresenta 17 etapas, gastando aproximadamente 110 minutos, dos quais $66 \%$ desse tempo é desperdício. Como resultado desse estudo, o autor sugeriu 3 propostas para alteração do formato atual, a primeira era a mudança de comportamento ou ações simples do cidadão e do órgão público em estudo e com custo zero. A segunda sugestão seria a alteração de alguns procedimentos para a realização da vistoria, reduzindo de 14 para 6 etapas. E a terceira proposta incluía tecnologia no processo de vistoria, reduzindo de 14 para apenas 4 etapas.

\section{MÉTODO DA PESQUISA}

Nessa seção será apresentado o passo a passo da pesquisa e quais técnicas e ferramentas foram utilizadas com o intuito de verificar os resultados da aplicação do lean office no ambiente administrativo desse órgão público.

Essa pesquisa trata-se de um estudo de caso com objetivo exploratório, de abordagem qualitativa e de finalidade aplicada.

\subsection{Procedimentos operacionais}

Os procedimentos dessa pesquisa foram divididos em quatro etapas. $\mathrm{Na}$ primeira etapa consta uma revisão bibliográfica que traz conceitos pertinentes ao assunto. Nessa etapa ainda, foram verificados documentos desse órgão em estudo além da coleta de dados aliada a uma observação direta dos trâmites necessários 
para a produção dos serviços, após isso foi selecionado um serviço para ser estudado e mapeado.

$\mathrm{Na}$ segunda etapa, a partir das informações da primeira etapa, houve a elaboração do MFV atual do serviço selecionado e seu lead time.

A terceira etapa traz mudanças nos processos, a partir da constatação de atividades que não agregavam valor e nos desperdícios. Essa etapa utilizou como base princípios do lean office e também Tapping e Shuker (2010) que trazem os sete desperdícios em ambientes administrativos.

Na quarta etapa apresenta a elaboração do MFV futuro do serviço em estudo.

\subsection{Primeira etapa: revisão bibliográfica, dados e seleção de produtos}

Essa pesquisa trata da aplicação do lean office no ambiente público, o primeiro passo foi uma revisão bibliográfica que abordada conceitos e autores que trabalham com a manufatura enxuta (lean), lean office, administração pública e MFV principalmente em áreas administrativas.

A coleta de dados foi realizada por meio da observação direta, análise documental e dados disponibilizados no site do DETRAN, na intranet e no sistema de acesso restrito, pois o autor desse estudo foi funcionário da unidade de trânsito até meados de 2018, porém não interferiu em nenhum momento na pesquisa, somente observou os procedimentos e coletou os dados.

A observação direta foi realizada pelo autor na própria unidade de trânsito quando os outros 2 funcionários realizavam os trâmites administrativos. A análise documental foi realizada pelo autor no ato da produção do serviço solicitado pelo cidadão e na prestação de contas que essa unidade do DETRAN elabora mensalmente, a qual consta, a especificação e a quantidade dos serviços realizados por essa unidade de trânsito.

\subsection{Segunda etapa: MFV atual e cálculo lead time}

A partir dos dados disponibilizados pelos sistemas do DETRAN-SP, coletaram-se as informações dos serviços realizados nessa unidade e suas respectivas quantidades por mês e uma estimativa de seus leads time. Em seguida 
houve a seleção do procedimento a ser mapeado. Importante mencionar que antes da confecção do MFV, é necessário atentar-se às etapas mencionadas na figura 1 dessa pesquisa. Essa seleção segundo Roman et al. (2014) é importante quando há uma grande diversidade de serviços e consequentemente vários fluxos diferentes. Portanto, essa seleção é necessária, pois esse órgão realiza aproximadamente 50 tipos diferentes de serviços.

Essa fase do trabalho trata da parte operacional, pois com o auxílio de um papel e lápis desenhou-se o procedimento administrativo na unidade de trânsito de Cedral para a emissão do CRLV. Após a representação desse MFV atual e com a observação desses procedimentos administrativos, calculou-se o lead time desse processo, além da observação de atividades que não agregavam valor ao processo. Em seguida, foi elaborado um plano de ação com a finalidade de minimizar ou ainda resolver os principais problemas verificados nesse processo.

\subsection{Terceira etapa: Plano de ação}

Após a análise dos documentos desse órgão público, da observação direta e do mapa atual; aliado aos princípios do lean office, possibilitou-se a identificação de alguns procedimentos e exigências que não agregavam valor ao serviço oferecido ao cidadão. Com a finalidade de facilitar a visualização dos desperdícios, embasouse no Tapping e Shuker (2010) que relatam os sete desperdícios do meio administrativo.

A partir disso, priorizou-se a remodelação dos trâmites para a emissão do CRLV, pautando nas leis e nas normas do setor público e desse órgão em estudo. $A$ reformulação desse serviço também contou com um investimento em tecnologia o qual será explicitado ao longo dessa pesquisa.

\subsection{Quarta etapa: MFV futuro}

Nessa última fase da metodologia é elaborado o MFV futuro, ou seja, a partir do MFV atual, é projetado o estado futuro. Esse novo mapeamento é realizado após o plano de ação que consta de ferramentas e princípios do lean office além de investimentos em tecnologia como computadores e softwares. 


\section{ESTUDO DE CASO}

O estudo de caso foi realizado em um órgão público estadual, DETRAN, o qual possui 336 Ciretrans e 309 Seções de Trânsito, as quais estão espalhadas pelos municípios paulistas. Diante desse grande número de unidades, foi selecionada a unidade de trânsito do DETRAN localizada em Cedral para a realização desse estudo.

Tal escolha foi motivada, pois essa unidade se mostrou aberta a processos de melhoria e ações foram implantadas nesse sentido. Observa-se também que Cedral segundo o Instituto Brasileiro de Geografia e Estatística (IBGE) possui uma população estimada de 9125 habitantes para 2018, portanto a cidade e essa unidade são de pequeno porte. Além disso, um dos autores dessa pesquisa foi funcionário dessa unidade por quase 10 anos e também por atualmente ser vereador desse município. Tais fatos colaboram para o acesso as informações necessárias para esse estudo junto ao órgão de trânsito e junto à administração pública municipal e estadual.

Os dados dessa pesquisa foram coletados de forma eletrônica no site do DETRAN, pela análise documental e observação direta da prestação de contas do setor público auxiliado pelo sistema PRODESP/DETRAN.

\subsection{Escolha dos processos mapeados}

A unidade de trânsito de Cedral conta com diversos serviços relacionados a trânsito como: a emissão de CRLV foco do processo a ser mapeado, emissão do Certificado de Transferência de Veículo (CRV), $2^{\underline{a}}$ via CRV, registro de veículo $0 \mathrm{~km}$, baixa permanente em veículo danificado ou irrecuperável, substituição de placas e tarjetas, liberação de veículos apreendidos em fiscalização de trânsito, autorização para remarcação de chassi e motor, emissão de CRV para fins de inclusão de alienação, bloqueio de veículos suspeitos de duble, expedição de contrato de comodato, vistoria em veículos escolares. Além desses serviços essa unidade realiza cadastros e recurso de infração de trânsito, renovação e mudança de categoria da Carteira Nacional de Habilitação $(\mathrm{CNH})$, certidão da $\mathrm{CNH}$, atualização e inserção de restrição na $\mathrm{CNH}$ de pessoas com deficiência, permissão internacional

Revista Produção Online. Florianópolis, SC, v. 20, n. 2, p. 368-397, 2020 
para dirigir no exterior, consulta de pontuação da $\mathrm{CNH}$, indicação de condutor (transferência de pontuação), obtenção da 1aㅡ $\mathrm{CNH}$, suspensão e cassação da $\mathrm{CNH}$ administrativa ou judicial, exame teórico (prova) para renovação da $\mathrm{CNH}$ e para $1^{\text {a }}$ $\mathrm{CNH}$, exame prático nas categorias $\mathrm{A}, \mathrm{B}$ e $\mathrm{D}$, expedição de cartão do idoso e cartão de deficiente físico, cadastramento e renovação de alvará de funcionamento para: despachante, autoescola, médico, psicólogo, empresas de desmontes, empresa de vistorias, empresas de emplacamento e também o recolhimento das taxas que envolvem todos esses serviços acima mencionados.

Diante desse vasto número de serviços selecionou-se o serviço de emissão de CRLV para ser estudado, observado e mapeado. Tal serviço foi escolhido por se tratar do mais demandado presencialmente na unidade de trânsito a partir de dados fornecidos pela própria unidade de trânsito.

Após a seleção do processo a ser estudado e a partir das observações dos trâmites administrativos realizados pelos funcionários da unidade de trânsito em estudo e na revisão bibliográfica dessa pesquisa principalmente o proposto por Tapping e Shuker (2010) elaborou-se um modelo análogo ao MFV, visando permitir um maior entendimento e visualização do processo administrativo em estudo, conforme forma gráfica da figura 3.

\subsection{Mapeamento do fluxo de valor atual-emissão CRLV}

A partir da figura 3, é possível visualizar os procedimentos administrativos para emissão do CRLV de forma presencial.

Figura 3 - Fluxograma atual para emissão CRLV

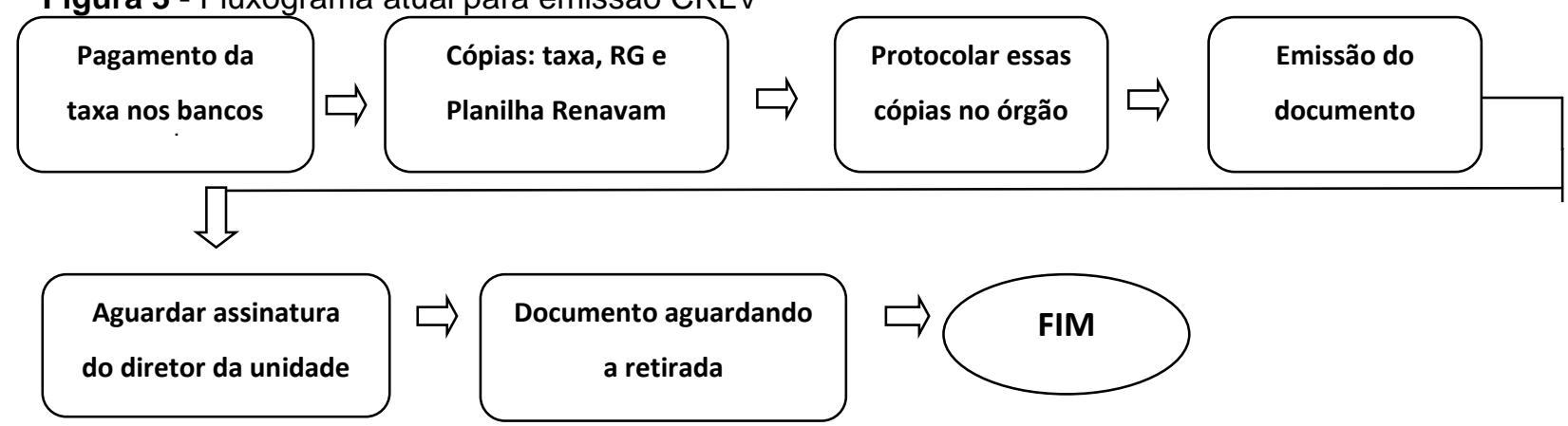

Fonte: Os próprios autores. 
A partir da análise da figura 3 , e dos trâmites realizados por esse órgão público, observa-se que todo cidadão que procura essa unidade para realizar a emissão do CRLV precisa dirigir-se a uma instituição financeira para realizar o pagamento da taxa, caso ainda não a tenha recolhida. Além disso, ele precisa tirar cópias dessa taxa recolhida e de um documento de identificação com foto: Registro Geral (RG), $\mathrm{CNH}$, passaporte, além de preencher uma planilha renavam disponível no site do DETRAN-SP e imprimi-la.

De posse desses documentos, o cidadão protocola o pedido de emissão do CRLV, em seguida esses documentos são direcionados ao setor de emissão. Após a emissão, o CRLV fica aguardando a assinatura do diretor. Somente após a assinatura é que o documento está disponível para o cidadão retirá-lo.

Com base no mapeamento atual, na observação direta e nos registros desse departamento, foi possível realizar o levantamento do lead-time da emissão do CRLV. Durante a realização desse serviço, o tempo transcorrido para que o pedido percorresse todas as etapas da cadeia produtiva até o requerente (cidadão) é considerado o lead time. $\mathrm{O}$ tempo estimado desse serviço é em média 2 dias úteis, prazo este informado ao cidadão no ato do protocolo.

$O$ início da contagem de tempo para esse lead time foi considerado quando o cidadão protocola no órgão o pedido para emissão do CRLV. A partir desse momento, os documentos protocolados, passam por uma conferência e posteriormente são encaminhados para a emissão do CRLV que precisa ser realizada em um computador e impressoras específicos. $O$ diretor permanece nessa unidade todas às terça e quinta feiras até às $12 \mathrm{~h}$, com isso os documentos protocolados, por exemplo, na segunda feira até às $12 \mathrm{~h}$ estarão disponíveis para retirada na terça feira. Além disso, os 2 bancos presentes em Cedral abrem às $10 \mathrm{~h}$ da manhã e possuem poucos funcionários; um deles apresenta somente 1 caixa e 0 outro 2 caixas para atendimento.

A partir da análise das etapas para a emissão desse certificado, verifica-se que a espera pela assinatura do diretor é o processo que apresenta a parcela mais significativa do lead time do processo. Todavia, essa assinatura não pode ser suprimida, pois é imprescindível para a validade do CRLV, não sendo possível deixar essas assinaturas em estoque.

A Figura 4 apresenta o MFV para a emissão de CRLV. 
Figura 4 - MFV atual para emissão de CRLV

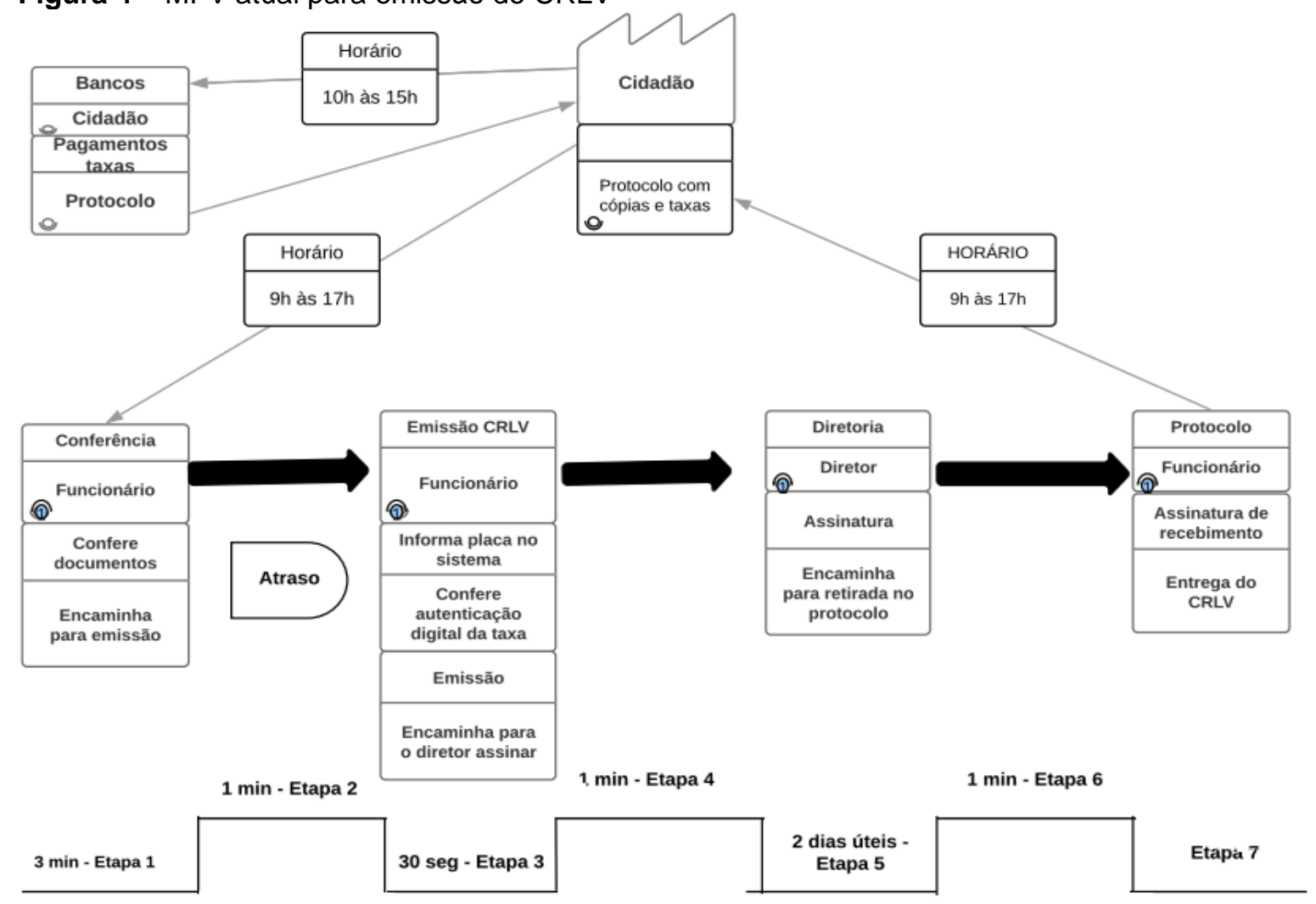

Lead time total $=2$ dias úteis $+5,5$ minutos, em média.

Fonte: Os próprios autores.

Considerando a figura 4, observa-se:

- Etapa 1: 3 minutos para o cidadão protocolar o pedido com as cópias dos documentos (taxa de licenciamento, documento com foto e a planilha renavam).

- Etapa 2: 1 minuto para o deslocamento do funcionário e dos documentos até o computador que realiza a impressão.

- Etapa 3: 30 segundos para o funcionário inserir os dados no sistema e realizar a emissão do CRLV.

- Etapa 4: 1 minuto para o deslocamento do funcionário e dos documentos até a mesa do diretor.

- Etapa 5: 2 dias úteis, em média, para o diretor assinar o CRLV.

- Etapa 6: 1 minuto para o deslocamento do funcionário com o CRLV assinado até o balcão de retirada.

- Etapa 7: Tempo para o cidadão receber o CRLV e assinar o comprovante de retirada. 
Os tempos anteriormente descritos foram estimados pelo autor dessa pesquisa, usando como referência, aproximadamente, 10 anos de trabalho nesse órgão público.

\subsection{Plano de ação com ferramentas de apoio do lean}

A partir da observação direta e da consulta documental (formulários, legislação específica e prestação de contas) aliado principalmente da elaboração e da análise do fluxograma e do MFV atual da emissão de CRLV e também apoiado nos conceitos e ferramentas do lean office sobretudo o MFV. A partir disso, permitiuse a identificação de algumas atividades já mencionadas que não agregavam valor ao processo. Além disso, algumas exigências desse órgão público que também não agregavam valor ao processo.

A partir desses desperdícios, priorizou-se a reformulação dos trâmites administrativos desse setor público. Essa reestruturação foi baseada nas leis, nas normas do setor público e desse departamento de trânsito. Além dessa alteração realizada nos procedimentos, a diretoria desse departamento realizou um investimento em tecnologia, informatizando alguns procedimentos inclusive o da emissão do CRLV.

\subsubsection{Plano de ação para emissão do CRLV}

A partir da análise dos procedimentos para emissão desse documento, foram excluídas algumas exigências como: cópias da taxa de licenciamento recolhida no banco, planilha renavam e a cópia do documento. Essas medidas só foram adotadas, pois esse órgão público alterou legislação específica excluindo as exigências acima mencionadas.

Além disso, foi realizado um investimento em tecnologia, instalando um sistema de pagamento de taxas de licenciamento na modalidade cartão de débito, ou seja, foi instalada 1 máquina de cartão de débito, 1 impressora térmica específica para taxas nessa unidade de trânsito. Aliado a isso foi instalado 1 novo software no computador dessa unidade que no ato da impressão do CRLV, automaticamente 
esse documento sai da impressora assinado. Sendo assim, não há mais a necessidade de esperar a assinatura do diretor.

\subsubsection{MFV futuro para emissão do CRLV}

A partir das mudanças administrativas realizadas e dos investimentos em tecnologia, os trâmites para emissão do CRLV na unidade de trânsito em estudo se tornaram mais simples, conforme figura 5.

A nova configuração desse serviço facilitou para o cidadão, pois ele pode realizar o pagamento da taxa de licenciamento (emissão do CRLV) dentro dessa unidade, não necessitando mais se dirigir até os 2 bancos presentes na cidade de Cedral-SP. Em seguida, ele entrega essa taxa mais um documento original de identificação com foto para o funcionário que se desloca até o computador e realiza a emissão do certificado que já sai assinado. A partir desse momento o CRLV está pronto para ser entregue ao cidadão. Diante disso, houve uma redução do lead time para emissão desse certificado. A figura 6 apresenta o MFV futuro para emissão de CRLV.

Figura 5 - Fluxograma futuro para emissão CRLV
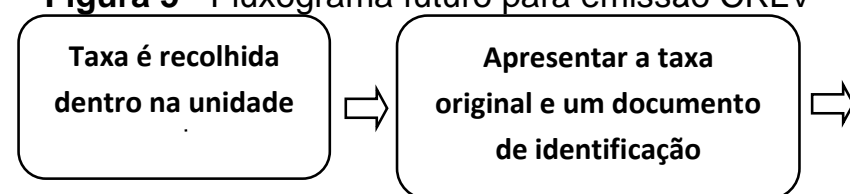
de identificação
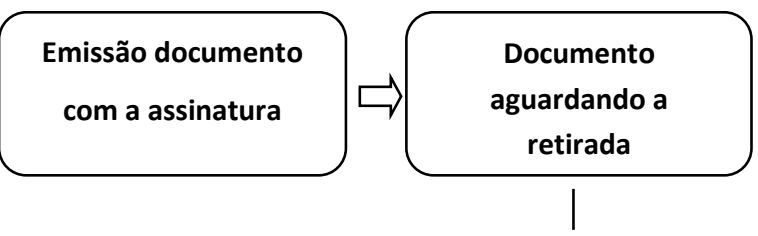

Fonte: Os próprios autores.

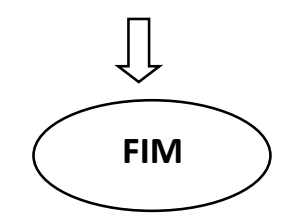


Figura 6 - MFV futuro para emissão de CRLV

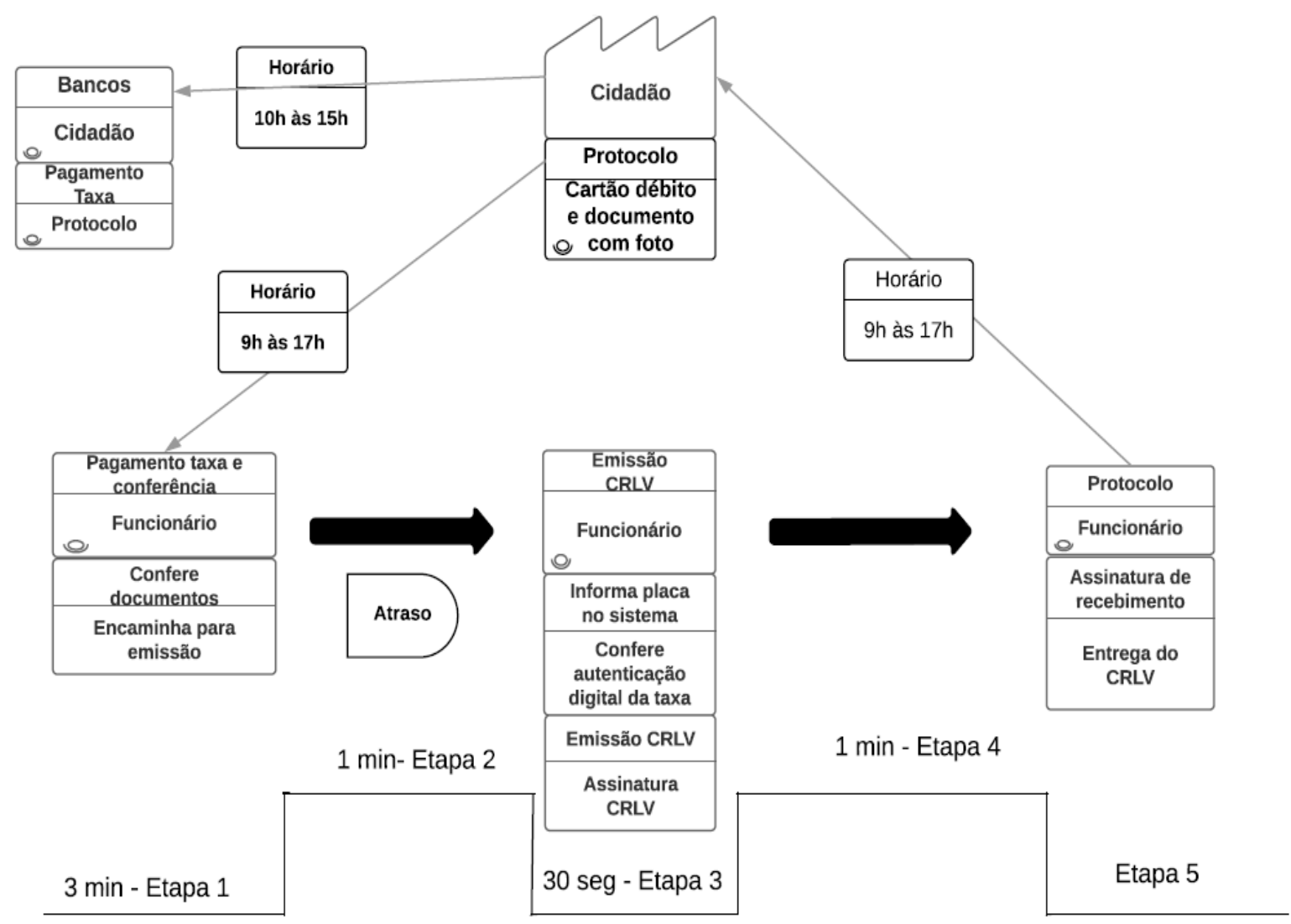

Lead time total $=5,5$ minutos + atraso.

Fonte: Os próprios autores.

A partir da figura 6 tem-se:

Etapa 1: 3 minutos para o pagamento da taxa e conferência do documento com foto do cidadão, serviços realizados pelo funcionário da unidade.

Etapa 2: 1 minuto para deslocamento do funcionário com a taxa até o computador que realiza a impressão. Como houve aumento da demanda, excepcionalmente, há atraso.

Etapa 3: 30 segundos para o funcionário inserir os dados no sistema e realizar a emissão do CRLV com a assinatura.

Etapa 4: 1 minuto para o deslocamento do funcionário com o CRLV assinado até o balcão de retirada.

Etapa 5: Tempo para o cidadão receber o CRLV e assinar o comprovante de retirada. 


\section{RESULTADOS E DISCUSSÕES}

O investimento estadual realizado nesse órgão público foi de $R \$ 106.679,98$, permitindo as seguintes alterações: local de atendimento (mudança de endereço), comunicação visual, novos mobiliários, equipamentos, sistemas, infra estrutura. Todavia, o investimento em tecnologia para a melhoria do serviço de emissão de CRLV foi bem inferior já que foram adquiridos: 1 máquina de cartão de débito, 1 impressora térmica específica para taxas, software para assinatura do CRLV conhecido como SEDI (Sistema de Emissão de Documentos Integrado) elaborado pela Prodesp (Companhia de Processamento de Dados do Estado de São Paulo). O valor estimado com esses equipamentos é de aproximadamente $R \$ 700,00$.

A partir da análise do fluxograma e dos MFV atual e futuro apresentados nessa pesquisa, observa-se que houve uma redução de procedimentos realizados pelo cidadão e pelos funcionários da unidade para a produção do CRLV, tornando o serviço menos burocrático. Além disso, o lead time desse serviço reduziu de 2 dias úteis para no máximo 1 hora, prazo este informando ao cidadão no ato do protocolo, sendo a média de 10 minutos. Essas modificações colaboraram para a redução dos sete desperdícios presentes no ambiente administrativo mencionados por Tapping e Shuker (2010) principalmente: a espera, estoque (com cópias desnecessárias) e transporte (de papéis).

A partir da análise da tabela 1 elaborada com os números fornecidos pela unidade de trânsito em estudo após consulta de sistema exclusivo do DETRAN-SP, nota-se que em 2017 foram emitidos 945 CRLVs e no ano de 2018 foram emitidos 3113, portanto, houve um aumento de mais de 3 vezes no número de emissão de CRLV. Um dos fatores desse aumento expressivo, pode estar relacionado com a considerável redução do lead time, após a implantação desses novos procedimentos que iniciaram no dia 14/11/2017.

Além do aumento da agilidade na emissão desse serviço, importante mencionar que houve uma redução no consumo de papel. Pois, antes dessa mudança, para a realização desse serviço eram necessárias 3 cópias (taxa de licenciamento, documento de identificação e planilha renavam), todavia, atualmente são exigidos os originais da taxa e do documento de identificação os quais são devolvidos para o cidadão. Portanto, somente nesse serviço foram economizados Revista Produção Online. Florianópolis, SC, v. 20, n. 2, p. 368-397, 2020 
aproximadamente 9400 folhas de papel no período de dezembro de 2017 até dezembro de 2018, contribuindo assim com a questão ambiental. Além disso, nesse período analisado somente esse serviço economizou aproximadamente $R \$ 500,00$ em papel sulfite. Na tabela 1 , segue a produção mês a mês para a emissão do CRLV.

\begin{tabular}{ccc}
\multicolumn{3}{c}{ Tabela 1- Estatística de emissão de CRLV } \\
\hline Mês & Ano & Quantidade \\
\hline Outubro & 2016 & 70 \\
Novembro & 2016 & 85 \\
Dezembro & 2016 & 81 \\
Janeiro & 2017 & 116 \\
Fevereiro & 2017 & 32 \\
Março & 2017 & 15 \\
Abril & 2017 & 55 \\
Maio & 2017 & 104 \\
Junho & 2017 & 78 \\
Julho & 2017 & 59 \\
Agosto & 2017 & 105 \\
Setembro & 2017 & 87 \\
Outubro & 2017 & 91 \\
Novembro & 2017 & 95 \\
Dezembro & 2017 & 108 \\
Janeiro & 2018 & 712 \\
Fevereiro & 2018 & 772 \\
Março & 2018 & 154 \\
Abril & 2018 & 141 \\
Maio & 2018 & 117 \\
Junho & 2018 & 143 \\
Julho & 2018 & 129 \\
Agosto & 2018 & 197 \\
Setembro & 2018 & 181 \\
Outubro & 2018 & 184 \\
Novembro & 2018 & 187 \\
Dezembro & 2018 & 196 \\
& & \\
\hline Fonte: Unidade trânsito-Cedral. \\
\hline
\end{tabular}

Em relação à demanda observa-se que a emissão de CRLV obteve um grande crescimento após a mudança, pois esse serviço pode ser realizado para todos os veículos do estado de São Paulo, conforme previsão de legislação específica do DETRAN-SP. Sendo assim, algumas empresas de cidades vizinhas como São José do Rio Preto, fizeram a emissão do CRLV da sua frota em Cedral. 
Tal fato pode ser observado a partir da análise da tabela 1 nos meses de janeiro e fevereiro de 2018.

Para garantir 0 atendimento do cidadão principalmente da demanda por serviços de emissão de CRLV e para atingir a meta estabelecida que é de no máximo 1 hora, essa unidade alterou seu horário de atendimento. Atualmente o atendimento ao público é das $9 \mathrm{~h}$ às $17 \mathrm{~h}$ sem interrupção para o almoço, com isso os funcionários se revezam em seu horário de almoço para garantir o atendimento.

A partir dessas mudanças e da redução do papel consumido, essa unidade de trânsito conseguiu reduzir seu arquivo pessoal, pois antes para cada CRLV emitido eram arquivadas 3 cópias, atualmente nenhuma cópia é arquivada. Outra alteração importante no DETRAN-SP foi o início do pagamento da Bonificação por Resultados (BR) embasado na Lei Complementar no 1079/2008. A partir dessa lei o DETRAN estabelece critérios e percentual para pagamento dessa bonificação, entre eles podemos citar: índice de modernização das unidades, índice de satisfação de atendimentos, índice de prestação de serviços on line, índice de recursos de autuações de trânsito, índice da operação direção segura, índice do fale com o Detran. Embora essa lei seja de 2008 somente a partir de 2013 que esse bônus começou a ser pago anualmente a todos os funcionários do Detran.

\section{CONCLUSÕES E CONSIDERAÇÕES FINAIS}

A presente pesquisa teve como objetivo identificar e analisar a aplicação de ferramentas do lean office no setor público estadual, em uma unidade de trânsito do DETRAN-SP. Para isso foi realizada uma revisão bibliográfica, abordando conceitos de administração pública e algumas características específicas desse setor, além de algumas métricas e passos para implantar o lean em ambientes administrativos.

Baseado nesses conceitos, os documentos dessa unidade foram analisados aliado a observação direta dos procedimentos de emissão de CRLV. Em seguida, realizou-se os mapeamentos de fluxo de valor desse serviço. Nesse mapeamento observaram-se operações, trâmites e exigências desnecessários. Sendo assim, novos procedimentos administrativos foram implantados nessa unidade de trânsito. De imediato, houve uma redução no lead time do serviço em estudo, além um aumento de demanda. Além disso, houve uma redução no consumo de papel por 
parte do cidadão que não precisa levar mais as cópias para a emissão do CRLV. Ou seja, essa alteração também colaborou para a questão ambiental já que muitas árvores serão poupadas, uma vez que ela é matéria prima para a produção de papel. Portanto, essas mudanças melhoraram os processos em estudo tanto qualitativamente quanto quantitativamente.

Diante do exposto, ficou evidente que algumas ferramentas e conceitos provenientes do lean office principalmente o mapeamento de fluxo de valor com as devidas adaptações para o setor público pode ser aplicado com sucesso. Essa melhoria nos processos já atingiu mais de 400 unidades das 645 presentes no estado de São Paulo, conforme (SÃO PAULO, 2018). Além disso, essas mudanças podem ser aplicadas em outros órgãos públicos e principalmente em órgãos de trânsito do Brasil.

\section{REFERÊNCIAS}

ALTOUNIAN, C. S. Obras públicas: licitação, contratação, fiscalização e utilização. 2. ed. rev. e ampl. Belo Horizonte: Fórum, 2009.

BORIOLO, R.O. Lean Office aplicado ao fluxo documental de uma Universidade Pública visando à adequação à Legislação. 2018. 153 f. Dissertação (Mestrado em Gestão de Organizações e Sistemas Públicos) - Programa de Pós Graduação em Gestão de Organizações e Sistemas Públicos. Universidade Federal de São Carlos, 2018.

BENETTI, H. P. Diretrizes para avaliar a estabilidade do fluxo de valor sob a perspectiva da mentalidade enxuta. 2010. $177 \mathrm{f}$. Tese (Doutorado em Engenharia de Produção) - Universidade Federal do Rio Grande do Sul. Porto Alegre, 2010.

CABETE, M. S. Gestão de acervo enxuto para bibliotecas escolares. $2016.76 \mathrm{f}$. Dissertação (Mestrado em Engenharia de Produção) - Programa de Pós Graduação em Engenharia de Produção, Universidade Federal do Amazonas, Manaus, 2016.

CARTER, Willie L. A lean office eliminates waste and saves time. 2010. Disponível em: https://www.qualitydigest.com/inside/six-sigma-article/lean-office-eliminates-waste-andsaves-time-062310.html. Acesso em: 05 abr. 2019.

CAMPOS, A. T.; QUEIROZ, J. A.; MONTEVECHI, J. A. B.; LEAL, F.; PEREIRA, A. P. Integração entre lean office e simulação a eventos discretos: um estudo de caso no setor de autopeças. In: SBPO., 48., 2016. [Anais...]. Vitoria, 2016. Disponível em: www.din.uem.br/sbpo/sbpo2016/pdf/156828.pdf. Acesso em: 02 abr. 2019.

COSTA R. S.; JARDIM E. G. M. Os cinco passos do pensamento enxuto net. Rio de Janeiro, 2010. Disponível em: www.trilhaprojetos.com.br/home/. Acesso em: 15 abr. 2019.

COSTA, M.T.P; MOREIRA, E. A. Gestão e mapeamento de processos nas instituições públicas: um estudo de caso em uma universidade federal. Revista GUAL, Florianópolis, v. 
11, n. 1, p. 162-183, jan. 2018. Disponível em: http://www.gual.ufsc.br. Acesso em: 25 fev. 2019. https://doi.org/10.5007/1983-4535.2018v11n1p162

CORREA, H. L; CORREA, C. A. Administração da produção e operações. São Paulo: Atlas, 2006.

EMILIANI, M.; STEC, D. Leaders lost in transformation. Leadership and Organization Development Journal, v. 26, n. 5, p. 370-387. https://doi.org/10.1108/01437730510607862

FADUL, E.; SOUZA, A. R. Analisando a interface entre o gerencialismo, a criação das agências reguladoras e a inovação institucional. In: ENAMPAD, 30., 2006. [Anais...] Salvador: ANPAD, 23 a 27 de setembro, 2006.

FONSECA, A. S. Direito administrativo: organização administrativa brasileira. Disponível em: www.fap

pb.edu.br/aluno/arquivos/material didatico/direito/administrativo/organizacao administrativa brasileira.pdf. Acesso em: 04 abr.2019.

FONTANINI, P, S. P.; PICCHI, F. A. Lean thinking em processos administrativos:

mapeamento do fluxo de aprovação de projetos na prefeitura. In: SIMPÓSIO BRASILEIRO DE GESTÃO E ECONOMIA DA CONSTRUÇÃO, 4., ENCONTRO LATINO AMERICANO DE GESTÃO E ECONOMIA DA CONSTRUÇÃO, 2005, Porto Alegre. [Anais...] Porto Alegre: SIBRAGEC, 2005.

GISSONI, L. R. M. Implantação de mapeamento de processos de trabalho no setor de transporte de uma instituição federal de ensino. 2016. 75 f. Dissertação (Mestrado em Administração Pública) - UNIFAL, Câmpus Varginha, 2016.

GUERREIRO, R. Princípios básicos da administração pública poderes, deveres, direitos e responsabilidades do servidor. São Paulo: FEAUSP,2013. Disponível em: www.ted.iqsc.usp.br/files/2015/03/Manual direito Administrativo FEA.pdf. Acesso em: 07 abr. 2019.

GOMES, R. C.; MARTINS, H. F. Tendências e perspectivas da administração pública no Brasil. Revista de Pesquisa em Políticas Públicas, Brasília, v.1, n.1, p.30-62, jul. 2013. https://doi.org/10.18829/rp3.v0i1.9127

GRONOVICZ, M. A.; BITTENCOURT, M. I. P.; SILVA, S. B. G.; FREITAS, M. C. D.; BIZ, A. A. Lean Office: uma aplicação em escritórios de projetos. Gestão e Conhecimento, v.7, n.1,p. 48-74, jan./jun.2013.

HINES, P.et al. Value Stream management: strategy and excellence in the supply chain. Financial Times Prentice Hall, Harlow:2000.

KRINGS, D.; LEVINE, D. AND WALL, T. The use of lean in local government, PM Public Management, v. 88, n. 8, p. 12-17, set. 2006.

KUHN, A. Qualidade e licitação de obras públicas: uma análise crítica. 97 f. Dissertação (Mestrado em Engenharia Civil) - Programa de Pós-Graduação em Engenharia Civil, Universidade Federal Fluminense, Niterói - RJ, 2002.

LAGO, N.; CARVALHO, D.; RIBEIRO, L. M. M. Lean Office. Revista Fundição, n. 248/249, p.6-8, 1 e 2 trimestre, 2008. Disponível em:

www.lean.dps.uminho.pt/ArtigosRevistas/LeanOfice.pdf. Acesso em: 01 fev. 2019.

Revista Produção Online. Florianópolis, SC, v. 20, n. 2, p. 368-397, 2020 
LAREAU, W. Office Kaizen: transforming office operations into a strategic competitive advantage. Wisconsin, EUA: ASQ Quality Press, 2002

LIMA, C. A. N. Administração pública. 2. ed. rev. Rio de Janeiro: Elsevier, 2008.

LIMA, M. M. X.; BISIO, L. R. A.; ALVES, T. C. L. Mapeamento do fluxo de valor do projeto executivo de arquitetura em um órgão público. Gestão \& Tecnologia de Projeto, v.5, n.1, p. 24-55, jul. 2010. https://doi.org/10.4237/gtp.v1i1.113

LOPEZ, E. A.; REQUENA, G.; LOBERA, A. S. Lean Service: reassessment of lean manufacturing for service activities. Procedia Engineering, 132, p. 23-30, 2015. https://doi.org/10.1016/j.proeng.2015.12.463

McMANUS, H. (2003) Product development value stream analysis and mapping manual (PDVMS) -Alpha Draft. Cambridge: Massachusetts Institute of Technology.

MANOS, T. Value stream mapping: an introduction. Rio de Janeiro: Quality Progress, 2006.

MAZZA, A. Manual de direito administrativo. São Paulo: Saraiva, 2011, p.30-35.

OLIVEIRA, R. B. B.; CORRÊA, V. A.; NUNES, L. E. N. P. Mapeamento do fluxo de valor em um modelo de simulação computacional. Revista Produção Online, v.14, n.3, p.837-891, 2014. https://doi.org/10.14488/1676-1901.v14i3.1461

OLIVEIRA, A. C. M.; DINIZ, J. A.; BISPO, J, S.; LIMA, S. C.; SANTOS, L. C. Impacto da descentralização na economicidade de compras governamentais. Revista Contabilidade e Controladoria (RC\&C) , Curitiba, v. 9, n. 2, p. 44-58, maio/ago. 2017. https://doi.org/10.5380/rcc.v9i2.50616

OHNO, T. O. O sistema Toyota de produção: além da produção em larga escala. Porto Alegre: Bookman, 1997. 150 p.

PAGNOSSIN, L, G.; ROSS, C. Abordagem do lean office aplicada em um caso prático. Journal of Lean Systems, 1, p. 95-113, 2016.

PEREIRA, J. M. Manual de gestão pública contemporânea 4. ed. São Paulo: Atlas, 2012.

PISA, B. J; OLIVEIRA, A. G. Gestão de projetos na administração pública: um instrumento para o planejamento e desenvolvimento. In: SEMINÁRIO NACIONAL DE PLANEJAMENTO E DESENVOLVIMENTO, 1., 2013. [Anais...]. Curitiba: PPGP/UTFPR, 2013.Disponível em: www.eventos.ct.utfpr.edu.br/anais/snpd/pdf/snpd2013/Beatriz Jackiu.pdf. Acesso em: 05 abr. 2019.

PINTO, J. P. Pensamento lean: a filosofia das organizações vencedoras. 2. ed. Lidel, 2009.

PLANALTO (2018). Constituição da República Federativa do Brasil. Disponível em: www.planalto.gov.br/ccivil 03/constituicao/constituicaocompilado.htm. Acesso em: 30 mar. 2019.

PRATES, C. C.; BANDEIRA, D. L. Aumento de eficiência por meio do mapeamento do fluxo de produção e aplicação do índice de rendimento operacional global no processo produtivo de uma empresa de componentes eletrônicos. Gestão e produção. São Carlos, SP,v.18, n.4, p.705-718, 2011. https://doi.org/10.1590/S0104-530X2011000400003

Revista Produção Online. Florianópolis, SC, v. 20, n. 2, p. 368-397, 2020 
ROMAN, D. J.; MARCHI, J.; FORCELINI, F.; ERDMAN, R. H. Lean service: aplicação do mapeamento do fluxo de valor em uma organização de serviços. Revista Gestão Industrial, v.9, n.4, 2014. https://doi.org/10.3895/S1808-04482013000400005

ROMUALDO, M.V.S. Aplicação do mapeamento do fluxo de valor ao processo de vistoria veicular do Detran RJ como ferramenta de melhoria da experiência do consumidor/cidadão. 2018. 91 f. Projeto de Graduação (Graduação em Engenharia de Produção) - Programa de Graduação em Engenharia de Produção, da Escola Politécnica da Universidade Federal do Rio de Janeiro, Rio de Janeiro, 2018.

ROTHER M.e SHOOK J., Learning to see: Value stream mapping to add value and eliminate muda. 2 Edition, Brookline, MA; The Lean Enterprise Institute Inc, 1999.

ROTHER, M.; SHOOK, J. Aprendendo a enxergar: mapeando o fluxo de valor para agregar valor e eliminar o desperdício. São Paulo: Lean Institute Brasil, 2009.

ROTHER, M.; SHOOK, J. Aprendendo a enxergar: mapeando o fluxo de valor para agregar valor e eliminar desperdícios. São Paulo: Lean Institute Brasil, 2012.

SARTOR, V. V. B. Globalização e as Reformas nos aparelhos estatais. In: ENANPAD, 22., 1998. [Anais...]. Foz do Iguaçu: ENANPAD, 1998.

SECCHI, L. Modelos organizacionais e reformas da administração pública. Revista de Administração Pública, Rio de Janeiro, RJ, v.43, n.2, p.347-369, mar./abr.2009. Disponível em: www.scielo.br/pdf/rap/v43n2/v43n2a04.pdf. Acesso em: 15 abr 2019. https://doi.org/10.1590/S0034-76122009000200004

SLACK, N.; CHAMBERS, S. HARLAND, C.; HARISSON, A.; JHONSTON, R. Administração da Produção. 1. ed. São Paulo: Atlas, 1999.

SHOOK, J. Gerenciando para o aprendizado: usando o processo de gerenciamento A3 para resolver problemas, promover alinhamento, orientar e liderar. São Paulo: Lean Institute Brasil, 2008.

SOLDING, P.; GULLANDER, P. Concepts for simulation based value stream mapping. In: WINTER SIMULATION CONFERENCE, 2009. [Proceedings...]. Austin, Texas, p. 2231223, 2009. https://doi.org/10.1109/WSC.2009.5429185

TAPPING, D.; SHUKER, T. Lean Office: gerenciamento de fluxo de valor para áreas administrativas - 8 Passos para planejar, mapear e sustentar melhorias lean nas áreas administrativas. São Paulo: Editora Leopardo, 2010.

TEGNER. M. G.; LIMA. P. N.; VEIT. D. R; CORCINI NETO, S. L. H. Lean office e BPM: proposição e aplicação de método para a redução de desperdícios em áreas administrativas. Revista Produção Online, Florianópolis, SC, v. 16, n. 3, p. 1007-1032, jul./set. 2016. https://doi.org/10.14488/1676-1901.v16i3.2308

TURATI, R. C. Aplicação do Lean Office no setor administrativo público. 2007. 122 p. Dissertação (Mestrado em Engenharia de Produção) - Escola de Engenharia de São Carlos, Universidade de São Paulo. São Carlos, 2007.

WELO, T; RINGEN, G.Investigating Lean development practices in SE companies: A comparative study between sectors. Procedia Computer Science, v. 44, p. 234-243, 2015. https://doi.org/10.1016/j.procs.2015.03.056

Revista Produção Online. Florianópolis, SC, v. 20, n. 2, p. 368-397, 2020 
WOMACK, J. P.; JONES, D. T. A mentalidade enxuta nas empresas: elimine o desperdício e crie riqueza. 1a.ed. Rio de Janeiro: Campus, 1998. p. 427.

WOMACK, J. P.; JONES, D.T.; ROOS, D. A Máquina que mudou o mundo. 11. ed. Rio de Janeiro: Campus, 2004.

VIANA, M. S. Do modelo burocrático ao gerencial: o exemplo de Mato Grosso. Cáceres: Unemat, 2005.

ZAKI, B. R. Proposta de método de gerenciamento de processos administrativos para organizações prestadoras de serviços. 2009. 80 f. Dissertação (Mestrado em Engenharia Mecânica) - Universidade Estadual de Campinas, São Paulo.

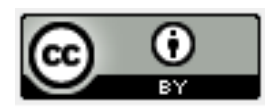

Artigo recebido em: 05/05/2019 e aceito para publicação em: 04/03/2020

DOI: http://dx.doi.org/10.14488/1676-1901.v20i2.3641 